\title{
Avances ambientales del sector pesquero
}

\section{Richard I nurritegui B. *}

En el presente artículo, Richard

Inurritegui analiza el mercado y el sector pesquero peruano desde una perspectiva ambiental. Se exponen los diferentes avances en el cuidado del medio ambiente y la responsabilidad empresarial dentro de este ámbito, así como los retos que impone el futuro de este sector. Asimismo, se hace hincapié en las regulaciones que tiene esta determinada actividad económica y el rol que juega el Estado en ella.

Bachiller en Derecho por la Pontificia Universidad Católica del Perú (1989) y Abogado desde 1996. Consultor del Estudio Rodrigo, Elías \& Medrano. Fue presidente de la Sociedad Nacional de Pesquería (2011-2013). 


\section{Avances ambientales en el sector pesquero}

La explotación de recursos naturales es uno de los temas que más sensiblemente se percibe por parte de la población. Esto se debe a que conforme lo establece la Constitución Política del Estado y la Ley Orgánica de Aprovechamiento Sostenible de los Recursos Naturales - Ley 26821, los recursos naturales pertenecen a la Nación, es decir, a todos los peruanos y por tanto quienes ostentan derechos de concesión para el uso y disfrute de estos recursos, tienen la obligación de cuidarlos y explotarlos racionalmente y en forma sostenible.

Esto es aún más sensible en el caso del sector pesquero por cuanto se trata de recursos naturales "renovables", por lo que su sostenibilidad y garantía de permanencia por renovación, impone una doble obligación de cuidado a los que los explotan.

El aspecto ambiental ha sido también en el sector pesquero un tema sensible por años. El hecho que las plantas de harina y aceite de pescado (principal industria del sector pesquero) descargue sus efluentes al mar y que estas plantas emanen humos al aire, las ha hecho visibles a una necesaria legislación ambiental que regule que el impacto al entorno sea el menor posible (quién en el pasado y viajando hacia el norte, no pasó por Chimbote en temporada de pesca y pudo percibir ese olor característico a harina de pescado; el olor a prosperidad decían los chimbotanos).

El sector pesquero comprendió además que el asumir compromisos ambientales y trabajar en el diseño de las principales normas ambientales, pasaba no solamente por la necesaria obligación de realizar una actividad cuidando y protegiendo el entorno ambiental, sino también que la inversión en nueva tecnología para el cumplimiento de los compromisos ambientales y la normativa, podía dar réditos en un mejor aprovechamiento de la materia prima y con ello más eficiencia si se reducían los vertimientos de sólidos y grasas.

Así por ejemplo y ello se puede apreciar del gráfico debajo, en los años 60's se desperdiciaba aproximadamente el $36 \%$ de la materia prima recibida en el proceso de fabricación de harina y aceite y hacia el año 2012 y luego de varios procesos de implementación de nuevas tecnologías, sólo se desperdiciaba el $0.1 \%$. Esta diferencia de desperdicio ha significado un mayor aprovechamiento de los sólidos y grasas y con ello un mayor beneficio económico por la mayor cantidad de volumen de producto final que se obtiene con la misma cantidad de materia prima. 


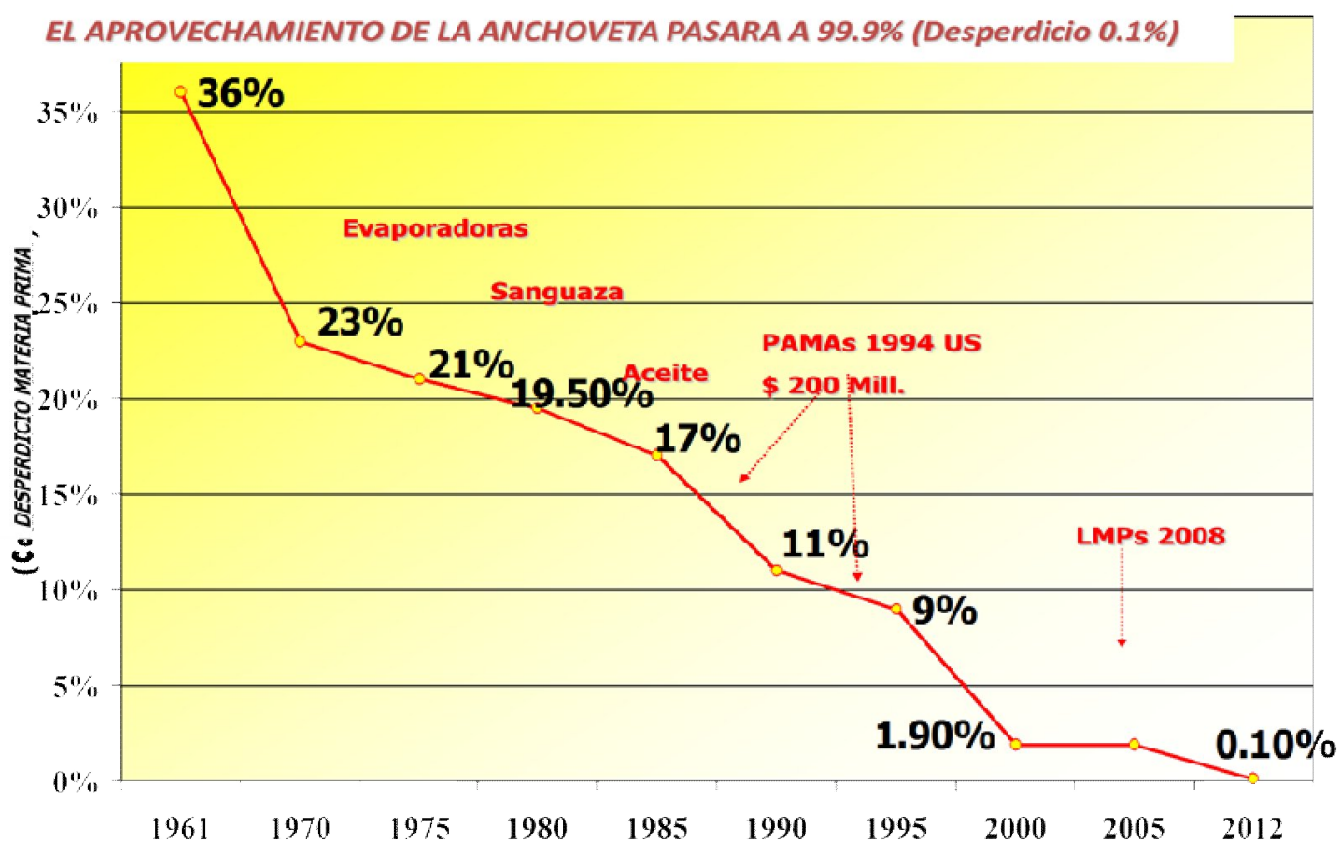

El primer proceso importante y de relevancia de implementación de tecnología ambiental en el sector se dio en el año 1994, con la implementación de los PAMA's Programa de Adecuación y Manejo Ambiental que supuso una inversión de US\$200 millones.

En la década pasada y luego de un arduo trabajo técnico coordinado entre el sector privado representado por la Sociedad Nacional de Pesquería y la autoridad ambiental sectorial de entonces, la Dirección General de Medio Ambiente, se logró establecer los parámetros adecuados para la industria de harina y aceite de pescado en relación a los límites máximos permisibles de los efluentes que se podían verter en el cuerpo marino receptor. Estos límites fueron finalmente aprobados mediante Decreto Supremo 0102008-PRODUCE y establecieron para las plantas un plazo de implementación de 4 años contados desde que el Ministerio de la Producción aprobara la actualización del plan de manejo ambiental y en forma inmediata, para las plantas nuevas o las que se reubicaban.

Posteriormente se aprueban mediante Decreto Supremo 011-2009-MINAM, los límites máximos permisibles para las emisiones al aire de la industria de harina y aceite de pescado. En este caso, el plazo de implementación era de 3 años desde la implementación de la "Guía del Plan de Manejo Ambiental para alcanzar los LMP" e inmediato para las plantas nuevas o las que se reubicaban.

Otro hito importante a destacar en el tema ambiental pesquero es la normativa que dispone la obligatoriedad de la Innovación Tecnológica en las plantas, que implicó el cambio obligatorio del sistema de quemado a fuego directo por el sistema de quemado 
a vapor indirecto. Esto se estableció mediante las Resoluciones Ministeriales 621-2008PRODUCE y 242-2009-PRODUCE. Este nuevo sistema ahorra un $30 \%$ de energía, reduce más del $99 \%$ de las emisiones y determina un producto final con mayor calidad nutricional. Esto ha determinado además que el sector pesquero sea el único sector nacional con tecnología ecoeficiente obligatoria.

Finalmente, y en cuanto a compromisos ambientales en el sector pesquero se refiere, hay dos hitos importantes de iniciativa privada de implementación de mejoras en beneficio del entorno ambiental donde operan. Se trata de las iniciativas de emisores submarinos en dos bahías que son muy sensibles y que han supuesto una fuerte inversión por parte del sector privado.

La primera de estas iniciativas se dio en la bahía de Paracas y la obra se culminó en el 2004. Allí las 7 empresas pesqueras de la zona crearon una entidad llamada APROPISCO y construyeron con una inversión de US\$ 8 millones, un emisor submarino de 13 kilómetros que vierte los efluentes de las plantas fuera de la bahía, efluentes que son previamente tratados. En la práctica, es como si las plantas pesqueras ya no estuvieran en la bahía de Paracas.

La segunda de ellas se dio en la bahía El Ferrol (Chimbote) y se finalizó en el 2013. Bajo el mismo esquema pero con un número mucho mayor de plantas (40), agrupadas como APROFERROL primero y ahora con la denominación de APROCHIMBOTE, invirtieron US\$ 15 millones para construir un emisor submarino de casi 11 kilómetros que vierte los efluentes fuera de la bahía. En el presente caso y dada la complejidad por la cantidad de plantas, el sector privado y el sector público convinieron en la necesidad de regular esta iniciativa con una norma que fue el Decreto Supremo 0202007-PRODUCE.

Todo este proceso que en apretado resumen se ha descrito, ha supuesto sólo en el quinquenio comprendido entre los años 2009 y 2013, una inversión de US\$ 500 millones para el sector pesquero, los que sumados a los US $\$ 200$ millones invertidos en la década de los $90^{\prime} \mathrm{s}$, a pesar de períodos difíciles para el sector como el Fenómeno El Niño de 1998, demuestran un sector comprometido con el tema ambiental. 


\section{INVERSIONES AMBIENTALES 2009-2013 (US \$ Millones)}

\begin{tabular}{|c|c|}
\hline & $\begin{array}{c}\text { Total Ejecutado } \\
\mathbf{2 0 0 9 - 2 0 1 3}\end{array}$ \\
\hline LMPs Efluentes & 145.0 \\
\hline LMPs Emisiones * & 340.0 \\
\hline $\begin{array}{r}\text { Chimbote } \\
\text { (PACPE) }\end{array}$ & 15.0 \\
\hline $\begin{array}{r}\text { TOTAL US \$ } \\
\text { MILLONES }\end{array}$ & $\mathbf{5 0 0 . 0}$ \\
\hline
\end{tabular}

Como puede apreciarse, la industria de harina y aceite de pescado cumple con una normativa ambiental que ha sido diseñada para que dicha industria opere en forma amigable con su entorno tanto marino como aéreo, consolidándose como una industria moderna y de calidad. Recuerdo que hace unos 10 años y con motivo de las injustas restricciones a la harina de pescado en la Unión Europea por la enfermedad Encefalopatía Espongiforme Bovina (EEP), más conocida como la enfermedad de las "vacas locas", logramos traer a un grupo de parlamentarios de la Unión Europea para que conozcan las plantas y sus procesos productivos y quedaron impresionados con el nivel de tecnología, eficiencia y cuidado ambiental de las mismas, verificando que se hacía un producto de calidad $100 \%$ de pescado sin posibilidad de contaminación cruzada, lo que redundó en una imagen positiva del sector y el inicio del levantamiento de la injusta restricción.

En la actualidad se está implementando la normativa para establecer los límites máximos permisibles de efluentes para la industria pesquera de consumo directo (conservas, congelado y curado). Ya existe un proyecto que ha sido pre-publicado para opinión de os interesados y próximamente se convertirá en una norma de cumplimiento obligatorio que culminará el proceso de normativa ambiental del sector pesquero en su totalidad. 